\title{
Business Rules Mining Using GUHA Method for the Personalization of Commercial Offers
}

\author{
Stanislav Vojir, Zdenek Smutny
}

\author{
University of Economics, Prague \\ W. Churchill Sq. 1938/4, 13067 Prague 3, Czech Republic \\ E-mail.stanislav.vojir@vse.cz; zdenek.smutny@vse.cz
}

cross $^{\text {ref }}$ http://dx.doi.org/10.5755/j01.ee.28.2.15767

\begin{abstract}
A shift from mass to personalized marketing, and thus also to personalized offers, brings firms an advantage for building customer relationships. The article introduces an artefact in the form of a method for creating personalized offers, focused on companies engaged in e-commerce. This method is based on mining association rules using the GUHA method. The association rules are converted into business rules and then combined with other manually defined business rules. The application of the method in practice is illustrated on customers' data from the e-shop of a company doing business in navigation systems, for the purpose of selecting personalized offers for an e-mailing campaign. The practical illustration uses a combination of the data mining system LISp-Miner and the business rule system JBoss Drools, which are freely available tools. The advantages and limitations of the proposed method, in connection with creating personalized marketing strategies in e-commerce, are discussed. The purpose of this practically oriented article is to address marketing and account managers and the issues connected with the personalization of marketing activities.
\end{abstract}

Keywords: Business Rules, E-commerce, E-mailing, GUHA, Personalized Marketing, Personalized Offers, Rules Mining.

\section{Introduction}

It is becoming increasingly more difficult for retailers not only to acquire new customers, but also to maintain their position on the market, i.e. not to lose existing customers. The high level of competition, particularly in e-commerce, forces firms to expend their financial resources as effectively as possible, in which they are aided by various frameworks, models and indicators based on available historical data e.g. customer lifetime value or customer profitability (Estrella-Ramon et al., 2013). An important intangible asset of the firms is mainly their customers (Persson \& Ryals, 2010), which is reflected in the currently preferred customer-centric approach in relationship marketing (Fader, 2012). For this reason, a company's long-term value is expressed using also customer equity, which is most often defined as the sum of customer lifetime values of all current customers of a given company (Fader, 2012).

The aim of customer relationship management is mainly to retain current customers, build a long-term relationship with them, and only on that basis acquire new customers for the company (Ryals \& Knox, 2007). Firms should not overwhelm customers by e-mail offers and risk they would unsubscribe from e-mail newsletters, but rather send them a smaller number of offers that are as relevant as possible. Such efforts should be aided by the proposed artefact enabling commercial offer personalization. Personalization is understood as customization of the form or content of a communication (e.g. website, mailing) according to individual needs and individual values. It is mainly the marketing and account managers who face the question of how to suitably ensure this personalization, given the financial and technological possibilities of the company and its marketing strategy.
The research question posed in this article is typical for design science methodology (Wieringa, 2014). It concerns the design of a new artefact that would be applicable in personalized marketing and related strategies. The research question is: How to design a method for creating personalized offers based on the available data from previous purchases, which will help marketing and account managers to better achieve their marketing goals (e.g. activation of customers as part of customer retention strategy) by directly addressing their customers?

The purpose of this article is to devise a method for creating personalized offers that is technologically based on mining association rules using GUHA (General Unary Hypotheses Automaton) method (Hajek et al., 1966), converting them into business rules and then applying them in practice using JBoss Drools system (Red Hat, 2016). Using the method proposed in this article is empirically illustrated by the e-shop of the biggest Czech producer of navigation solutions. In addition to the main expected use of this method in the field of personalized marketing strategy in connection with personalized e-mailing campaigns, the same approach can also be used in other forms of automatic recommendation - e.g. personalizing the elements displayed on a website.

This article is divided into several parts. First, it outlines the areas of interest which this article builds upon - business rules and personalization of marketing activities. This is followed by introducing the methodological approach used in this work based on design science research. The conducted background research is used as a basis for defining the needs of firms in this area, and an artefact is then designed in the form of a method for creating personalized offers. In conclusion, the paper shows a 
practical use of the proposed method in the selected e-shop, and discusses the proposed method.

\section{Theoretical Background}

This section first discusses the issue of business rules and their application in practice, and then briefly introduces the area of personalizing marketing activities and related studies.

\section{Business Rules}

Business rules are simple intuitive rules and propositions defining or limiting come aspects of a company for the purpose of asserting company structure and influencing company performance (Hay et al., 2000). Using business rules in a firm is also a suitable approach to separating business logic from application logic and source codes (Ross, 2003). Business rules are most frequently used as an approach to modelling a company. Currently the most usual method of modelling a company is the procedural approach, which proceeds from global company goals through processes to their components. The business rules approach complements the models thus created by an inverse method, i.e. from bottom to top. The basic principle of this approach is: Rules build on facts, and facts build on terms (Ross, 2003, p. 165). The basic terms are first defined, on the basis of which facts are created, followed by business rules (Normantas \& Vasilecas, 2014).

The resulting rules can be used for communication (between workers, company's departments, or entire companies), as well as for active evaluation using business rule engine (direct decision management, launching promotion campaigns for events, etc.). A suitable place for connecting the business rule approach with company processes are their decision nodes, triggering events and end events in the case of process management (Zarghami et al., 2012).

From a technological perspective, business rules are not a single, concrete technology or specification. There exists a great number of specifications that differ in their focus - internal communication, creating decision support systems (Zamecnikova \& Kreslikova, 2016), evaluating application code, and others - and the types of rules that can be described by a given specification.

In current research activities there is an increasing number of efforts to expand the target area for implementing business rules, mainly into areas that are not completely covered by strict rules - see the study (Bosch, 2010). The main target areas in which using automatized business rules mining has a great potential is the area of risk management and marketing activities. This paper focuses on the latter.

\section{Personalization of Marketing Activities}

Among the current trends in data-driven analytical approach is also personalized marketing (Goldsmith \& Freiden, 2004), which focuses on creating a strategy using available customer data for creating personalized messages (e.g. offers, commercial communication) for current or potential customers. This approach abandons mass marketing campaigns and endeavours to target the content of a message at a specific customer as best as possible. But a substantial limitation from managers' perspective is the fact that this personalization means something else in every business (Vesanen, 2007). In other words, it is not a single universally applicable approach; instead, every personalization is carried out on a different level, looking at a straight line between mass and individual communication. The level of personalization thus depends on the type of enterprise, the available historical data, and the technologies used. For this reason, the present article focuses on companies engaged in e-commerce, as these companies have at their disposal a great amount of structured data about customers for a longer period of time.

Creating personalized marketing strategies is no doubt a current trend in e-commerce, as pointed out by the professional study (Teradata, 2015), but their technological provision is, despite that, not the subject of any more extensive research. When researching scientific papers, only 32 articles were found in Web of Science and 70 in Scopus that deal with the topic of personalized marketing, most of them not older than ten years. These articles can be divided according to the type of research into design and behavioural research.

The latter includes mainly quantitative studies focusing on the approach and behaviour of customers in connection with automatic product recommendations (Shen, 2014; Goldsmith \& Freiden, 2004), which includes mapping the development of their approach in time. Current studies focus on using available social data from several social media for a better personalization of messages (Bhardwaj et al., 2015) and they confirm the increasing emphasis on personalized marketing during a customer's purchase via the social media (Menon \& Sigurdsson, 2016). Current design type of research presents new artefacts (frameworks, models, methods etc.) focused on personalized marketing support, among others in the following areas: mobile marketing (Tang et al., 2013), marketing service in an interactive exhibition space (Bae et al., 2012), constructing a behavioural perspective model as a conceptual system for managerial decision making in e-mail marketing (Sigurdsson et al., 2016), or proposing a new method that can be used for selecting the best targets for cross-selling products (Guelman et al., 2015). The main output of this article also belongs to the design type of research.

It is very useful for companies to personalize advertisements according to available data on customer behaviour, because personalized advertisements are more effective than those which are not aimed at anyone in particular (Tucker, 2014). Similarly better results can be achieved by personalized advertising via mobile devices (Tang et al., 2013), in which it is necessary to take into account both the virtual and the physical context in which the mobile phone user is situated.

Despite the two examples above, personalization in marketing is not universally advantageous for any marketing activities. This holds true mainly in direct marketing where it is necessary to take into account the possible different attitudes of the defined customer target groups that a company wishes to address. The reason for this is the fact that every technology or space created by that technology is perceived differently by every generation (Smutny et al., 2017). 
This is exemplified by the results of a study by the company Amaze One in the UK (Gwynn, 2016). Their questionnaire survey was carried out on a representative sample of 2,647 UK adults in April 2016. While $57 \%$ people of Generation Y (18-34 year olds) was glad to receive personalized offers based on past purchases, in Generation $X$ and 0 (over 35) it was only $5 \%$ of the respondents. Marketing managers should always carefully consider the use of advanced methods and technologies, mainly in connection with a particular target group of customers. The older generations may show greater resistance to such offers, or even principally refuse them, because they might feel that as a violation of their privacy. On the other hand, based on a number of studies - e.g. (Becan \& Smutny, 2016; Moreno et al., 2015; Jones \& Shao, 2011; Xavier, 2011) - it can be said that the younger generations, starting with Generation $\mathrm{Y}$, tend to have a more positive relation towards new technologies, services and methods.

\section{Methodology}

This article is methodologically based in design science research (DSR). This type of research focuses on solving a problem by means of the design, construction and evaluation of an artefact. The task of such research is solving a problem that has been identified with a view to finding a satisfactory solution which, however, does not necessarily have to be entirely optimal (Dresch et al., 2015 , p. 68). DSR offers a high degree of relevance of the solution of a problem (e.g. organizational needs) with a rigorous approach to solution that uses existing knowledge bases and explicit procedures. There exists a number of different methodological approaches used in DSR and based on design science (Winter, 2008), of which the following two are very popular: Develop/Build Justify/Evaluate (Hevner et al., 2004); Awareness of problem - Suggestion - Development - Evaluation Conclusion (Vaishnavi \& Kuechler, 2015). In DSR a vast majority of methodological approaches uses four basic phases of research, on which this article is also based - (1) problem definition, (2) suggestion for possible solution, (3) development, and (4) evaluation (Dresch et al., 2015, p. 92).

The first phase of defining the problem is related to what was mentioned in Introduction and Theoretical background. E-commerce companies in particular exist in a hypercompetitive environment, in which the main goal is to retain current customers. In the interest of maintaining customer relationships, firms should send customers highly personalized offers in order to minimize the chance of them unsubscribing or ignoring the messages (Micheaux, 2011). E-mailing campaigns are an important tool for maintaining long-term relationships with customers. These two sections of the article justify the relevance of research, the importance of the problem, and the applicability of a solution based on available data and an approach based on business rules. The Introduction also presents the research question.

The second and third phase, focusing on the suggestion and development of a given solution, was in this article put together into the section below. This part introduces the method itself as well as the technological solution, which is used in practice in the next section. The evaluation of the artefact in the fourth phase is carried out in the Empirical illustration section, and is based on the outcomes of the practical application of the suggested method in the selected e-shop.

\section{Learning Business Rules from Company Data and Their Use in the Personalization of Commercial Offers}

A suitable type of analysis for acquiring business rules is using the possibilities of mining association rules. Association rules belong primarily to the topic of descriptive data mining (Rauch, 2013). Association rules enable analysing dependencies (associations) between individual attributes. The best known type of analysis using association rules is the shopping basket analysis, which enables finding relations between items purchased at the same time (Agrawal et al., 1993). Association rules can also be used for creating classification models (Bing et al., 1998), for example by using CBA algorithm (Classification Based on Associations). The discovered association rules are converted into the form of business rules for further use. As a prerequisite of the design itself, it is necessary first to define in greater detail the way of mining association rules, as well as the input data on which mining will be performed. Only then is it possible to proceed to the design of the method itself.

\section{Mining Association Rules}

Association rules can be acquired either in a simple form (the conjunction of individual items in the antecedent and consequent of a rule), obtained e.g. by using Apriori algorithm (Agrawal et al., 1993), FP-Growth (Tan et al., 2005, pp. 327-404), or in a more complex form using the procedures of the GUHA method (Hajek et al., 2010; Rauch \& Simunek, 2014).

Simple association rules in a relationship expressed by the general expression

\section{antecedent $\rightarrow$ consequent}

describe a relation (association) between the antecedent and the consequent of a rule. The antecedent and consequent being - in the case of shopping basket analysis - the set of items. To put it simply, it can be said that if a customer buys the items listed in the antecedent, they will also buy the items listed in the consequent. Also calculated in the rule are the values of the rate of interest, expressed by a formula defined above a four-square contingency table (see Table 1). The basic rates of interest are mainly Confidence and Support (see Table 2).

In such "simple" association rules, the antecedent and consequent part can contain one or more items. Classical algorithms for mining association rules (like Apriori) work only with data in transactional form. The results can then be formulated as:

$$
\{\text { product } 1, \text { product } 2\} \rightarrow\{\text { product } 3\}
$$

In the case of data in tabular form, the data have to be transformed into transactional form. Then the results can be formulated as: 


$$
\text { attribute } 1=A \& \text { attribute } 2=B \rightarrow \text { attribute } 3=C
$$

Apart from the well-known algorithms Apriori or FP-Growth, it is possible to use for finding association rules also algorithms that enable a more complex search for association rules. This paper uses the procedure $4 \mathrm{ft}$ Miner that is part of the system LISp-Miner, using the GUHA method.

GUHA is an original Czech method for finding interesting relations (hypotheses) in data. Although its principles were formulated as early as 1966 by Petr Hajek and his colleagues, its partial procedures are still being actively developed - see e.g. (Holena, 1998; Rauch \& Simunek, 2009; Berka, 2011; Piche et al., 2014; Berka, 2016; Rauch, 2013). In general, the method GUHA is used by many data mining procedures, see (Simunek et al., 2016). For the learning of association rules, the most suitable the procedure is 4ft-Miner. There are also procedures for decision trees, analysis of the dependencies of data attributes, cluster analysis - procedures CF-Miner, KL-Miner, SD4ft-Miner, KEX, ETree-Miner etc. The procedures of GUHA method are suitable for descriptive data analysis as well as for building active data mining models. For example, it is possible to mention the applications in such areas as credit risk management or anomaly detection in the data of health insurance companies. (Rauch, 2013; Rauch \& Simunek, 2014; Berka, 2016).

The procedure $4 \mathrm{ft}-$ Miner (based on an older procedure ASSOC) enables finding general association rules (Rauch, Simunek, 2001), expressed by the formula:

$$
\varphi \approx \psi / \chi
$$

where $\varphi, \psi$ and $\chi$ are logical combinations of attributes, and their relation is defined by the generalized quantifier $(\approx) . \varphi$ represents rule antecedent, $\psi$ is rule consequent (in GUHA method originally called succedent), and $\chi$ represents an optional condition that makes it possible to limit the data set that is being assessed. The 4ft-Miner procedure is implemented in the data mining system LISp-Miner, developed at the University of Economics, Prague. This procedure works with data in tabular, attribute-value form. The association rules gained using the procedure $4 \mathrm{ft}-$ Miner have a significantly higher expression power. The antecedent, consequent and optional condition part of association rules can contain not only the conjunction of individual attributes, but also disjunctions, negations and preferential grouping of attributes using brackets.

When using the procedure $4 \mathrm{ft}-$ Miner, individual attributes also do not have to contain only one specific value. The socalled dynamic binning can be used, in which a set is put in the rule attribute that is created by a dynamic combination of values - random, extreme, consecutive etc.

The "interestingness" of a found association rule is determined using the values of interest measures, or using the values of quantifiers. The individual quantifiers and the rates of interest based on them are characterized by formulas defined above a four-square contingency table (see Table 1), in which the individual letters represent the numbers of lines in a data set (e.g. the letter $a$ represents the number of lines that satisfy both the rule antecedent and consequent). Using the procedure $4 \mathrm{ft}-\mathrm{Miner}$, it is possible to use a greater number of different interest measures in one run (for example, a data mining expert is able to select only the rules that satisfy the conditions of the minimal value of interest measure Confidence, Support and also Lift at once).

Table 1

Four-square contingency table $-\varphi=$ antecedent, $\psi=$ consequent.

\begin{tabular}{|c|c|c|}
\cline { 2 - 3 } \multicolumn{1}{c|}{} & $\psi$ & $\neg \psi$ \\
\hline $\boldsymbol{D}$ & $\mathrm{a}$ & $\mathrm{b}$ \\
\hline$\neg \varphi$ & $\mathrm{c}$ & $\mathrm{d}$ \\
\hline \multicolumn{2}{|c|}{ Source: (Rauch \& Simunek, 2014) } \\
\hline
\end{tabular}

For mining association rules, it is necessary to choose also the rates of interest. Those selected for the task presented here are given in Table 2. Confidence determines the reliability of the relation between rule antecedent and consequent (to how many percent of records to which the rule antecedent applies, is the consequent also applicable). Support determines the percentage share of records to which the antecedent applies, to all records in the data matrix.

Table 2

Selected rates of Interest Suitable for Mining Association Rules

\begin{tabular}{|c|c|}
\hline Rate of interest & Definition \\
\hline Confidence / p-implication & $\frac{a}{a+b}$ \\
\hline Support & $\frac{a}{a+b+c+d}$ \\
\hline Above Average Dependence & $\frac{a(a+b+c+d)}{(a+b)(c+d)}-1$ \\
\hline
\end{tabular}

Source: (Rauch \& Simunek, 2014)

Above Average Dependence (AA-Dependence) refers to the fact that the relative frequency of lines satisfying the antecedent condition is at least $100 \mathrm{p}$ percent above the average frequency of lines satisfying the consequent condition in the entire data matrix ( $p$ being the value of AA-Dependence). AA-Dependence has a similar meaning to the better known rate of interest "Lift". The following relation applies:

\section{AA-Dependence $=$ Lift -1}

Apart from these (probably most frequently used) rates of interest, it is also possible to use several dozen other quantifiers, e.g. Chi-Square, Fisher, Below Average Dependence, p-equivalence, Double p-implication and others - see (Rauch \& Simunek, 2014).

\section{Required Data}

Every firm that operates an e-shop has at its disposal a large number of data regarding their customers. For the purposes of further analyses, it is convenient to divide attributes into several groups: 
The list of products, their mutual relations and categorization. In the case of cascade categories, it is suitable to include this information in the analysis - for the purpose of a suitable item grouping.

Order information - e.g. products purchased at the same time, numbers of simultaneously purchased pieces.

- Information about customers - even for unregistered customers, the e-shop usually has information about their name and address and whether the customer is natural or legal person. For logins via social networks it is possible to extend the data by a number of other information - e.g. a list of interests or friends. Acquiring this information is made easier for e-shops by the customers themselves, who - in exchange e.g. for a discount for providing access to their profile - share this information willingly (Smutny et al., 2017; Benson et al., 2015).

These data should then be supplemented by information about the success rate of previous marketing activities, e.g. the change of a number of products sold during a short-term sale or in connection with sending e-mail offers.

\section{Designing a Method for Creating Personalized Offers}

Companies engaged in e-commerce have two basic options for using personalized offers of products and services. Specifically, it is the offer or recommendation displayed on their website (e-shop), and the offer of products sent in the form of e-mail marketing messages. It is the latter that this article mainly focuses on. In the case of small firms and their e-shops, these offers are usually sent globally; larger firms use only basic customer clustering. But a large number of dispatched e-mails does not necessarily mean better marketing results - on the contrary, this leads to the customers ignoring a large number of e-mails (Micheaux, 2011).

By using business rules, it is possible to create a significantly more personalized offer that addresses the clients not with a global offer, but rather with a specific offer that is interesting for that particular customer. In order to create an interesting e-mail offer, a company can use only a limited number of items on offer; it is therefore essential to fill these few slots with highly suitable items.

The selection of suitable items can be seen as a decisive (or classifying) task which determines the suitability or unsuitability of including a particular item in a personalized offer. The whole procedure of compiling and sending an offer can be performed with the use of a business rule set. In practice the JBoss Drools system (Red Hat, 2016) can be used for this purpose. The procedure of compiling a personalized offer can be seen as a coherent method consisting of four steps:

1. Building a model for recommendation;

2. Adding manually entered business rules to the recommendation model;

3. Selecting suitable items with the best rate of interest to be included in the offer;

4. Adding other items and sending (e-mailing) or displaying the offer (web).

In order to build the model for recommendation, it is suitable to use association rules mining in the first step. When defining the task, the rule antecedent requires attributes representing customer characteristics and, for instance, previously purchased products. Attributes representing recommended products are expected in the consequent. The association rules that are found are arranged according to the values of rates of interest and antecedent length. If the number of rules found is too large, it is suitable to use the brCBA algorithm in order to reduce their number (Klieger et al., 2014). The association rules and their order (i.e. the specification of their priority) are then added to the business rule set used for recommendation.

In the second step of creating the recommendation model, it is possible to add manually entered rules to the process, or remove selected rules. This step should be applied, for instance, when it is necessary to sell a particular product that the e-shop needs to dispose of.

In the third step, all the manually entered as well as the found business rules are used for creating a stateless inference base within the business rule system. Rules are then integrated into this inference base that check the availability of the individual types of products, limit the total number of items, as well as control rules limiting for example the group of customers who are given the offer.

A network of effective evaluation of the activation of individual rules is created within the stateless inference base, which, however, does not change as specific facts are added or removed. The initial facts for inference are customer characteristics. On the basis of these characteristics, business rules are then activated, which add new items to the fact base, representing suitable types of products that should be included in the offer. The process of inserting a suggestion for a specific product (adding new facts) is limited by the business rules that check the availability of individual items in stock. In other words, from the marketing perspective it is inappropriate to offer users such products that are not in stock and will not be available in the near future.

The offer for a particular customer should not be limited only to the items that correspond to his or her customer profile or expected priorities, e.g. according to age or place of residence. In the fourth step, it is suitable to add to the list of items also some randomly generated item, or an item that is new for that area of market. The last component of a marketing offer can be a personalized offer of other services. When using data mining, it is possible to determine the preferred delivery method, which could then be offered at a reduced price.

From the technological perspective, in order to implement the designed artefact, the authors suggested and then used a combination of the data mining system LISp-Miner (http://lispminer.vse.cz) with the business rule system JBoss Drools (http://drools.org). In order to understand the data and for mining association rules, the used procedure was $4 \mathrm{ft}-\mathrm{Miner}$, implemented in the system LISp-Miner version 25.37.02. The GUHA association rules that were found were then exported to GUHA PMML format (Kliegr \& Rauch, 2010) and then, using XSL transformation, converted into DRL format. The DRL format is the default format of business rules for JBoss Drools system. Practical derivation used the component Drools Expert version 6 integrated into own Java EE code, making Drools functionality accessible by means of REST API. E-mail offers can be sent using Java or PHP code.

The answer to the research question from Introduction is also provided in this section, because it presents a 
principled proposal for creating a method that is technologically independent. The presented design of the method can thus be used also with other tools than those that are listed above. The next section introduces the evaluation of the method in practice according to design science methodology.

\section{Empirical Illustration}

In order to evaluate the suggested method, this study used order data from the e-shop of a producer and seller of GPS navigations including related accessories and map data. This is the biggest producer of navigation software and custom solutions in the Czech Republic. The following sections include a description of used data, a brief description of performed analyses and selected results or recommendations.

\section{Used Data and Their Preparation}

The analysis used primarily a table containing data about 3053 orders from 2010-2014, linked by M:N connection with a table containing the list of the products offered. Customer data were anonymized. All recorded data were not available for the purposes of the analysis, but a set of necessary attributes was defined prior to the analysis. The data used can be divided according to their characteristics into basic groups:

- Customer information (user ID, gender), ○ 2729 unique users;

- Information about order delivery (town/city and postcode from the billing address, delivery method, payment method),

- 1176 unique places of delivery;

- Product information (product ID, name, categorization),

$\circ$ the data contain 146 unique products.

Given the fact that the data were obtained from a real e-shop, it was necessary to cleanse the data of any duplicated and incorrectly entered information (mainly in the addresses) before any further analysis.

In order to find dependencies between individual purchased products, the data were combined in one table; to register information about the purchase of a particular product, the data were recorded as Boolean values in the column of the respective product. A basic analysis of the structure of the data revealed that, in terms of marketing activities, the e-shop in question has a considerable problem with the sell up of products. Most orders only contained a single product or a larger quantity of the same product. In terms of related items, the option of finding dependencies between subsequent orders of the same customer was used.

\section{Analysis of the Data}

The data analysis used the LISp-Miner system (Simunek et al., 2016), in which the analysis was performed using histograms. For the subsequent creation of the datamining model consisting of association rules, the procedure 4ft-Miner of the GUHA method was used. Rates of interest
AA-Dependence, Confidence and Support were used for finding rules. The acquired results were then transformed into business rules by two different methods: (1) manually obtaining the results of data mining for a manual creation of business rules, (2) automatic creation of recommendation rule set. Examples are given below.

Rules for manual transformation: Part of the knowledge acquired in the frequency analysis was transformed by manual transcription. The most significant of the discovered dependencies is the time between repeated purchases of the same user, the gap being 2 years in most cases. In general terms, the rules that were found can be interpreted using the following relation: "If a user bought a GPS navigation, then he or she usually buys an update of map data 2 years after the purchase." This rule can be transformed into the form of a business rule that defines the amount of time after which it is suitable to contact the user with an update offer.

Other temporal specifics of orders reveal interesting information concerning the sale of accessories (navigation holders etc.), in which there can be seen an increased interest of customers at the turn of January and February (see Figure 1). It can be supposed that this is in connection with "Christmas presents", which can be used for increasing the priority of product from that category in this period.

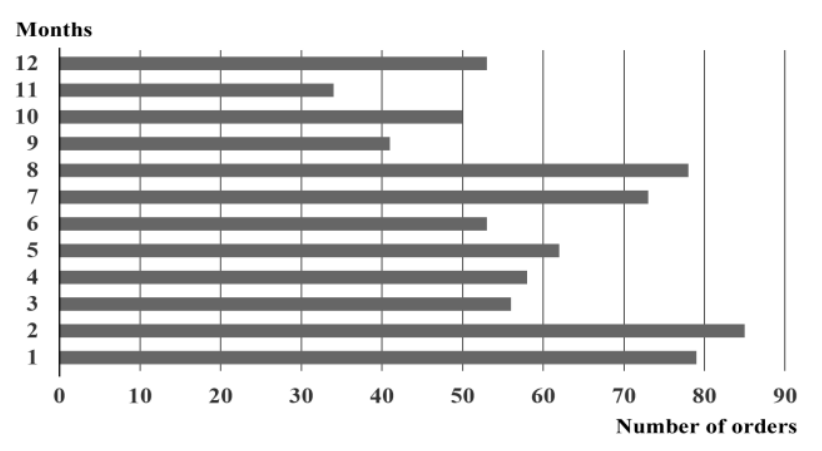

Figure 1. Number of Orders of Accessories According to Months in the Monitored Period

Source: Authors

Automatic creation of rules for recommendation: Another part of the knowledge, consisting of complete sets of association rules, can be transformed into business rules as part of an automatized process. The discovered rules can be used of the selection of suitable products according to basic customer characteristics (gender, place of residence etc.). The defined tasks were designed for finding deviations - products that were ordered with an above-average frequency. As an illustration, two of the discovered rules are given below:

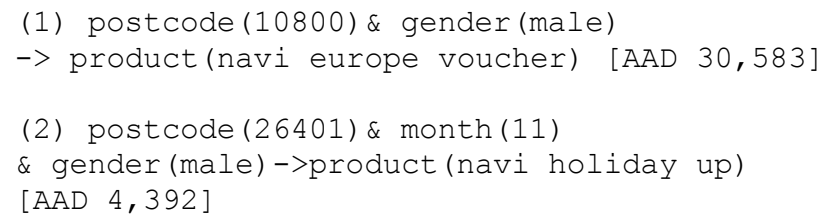

The AAD value in these rules represents the value of the AA-Dependence rate of interest, which is suitable for finding above-average dependencies and exceptions. The 
first rule states that men who have an address with the postcode 10800 are $3,058.3 \%$ more likely to purchase "navi europe voucher" than all the customers who purchased this product. Similarly, the second rule states that men making a purchase in November who have the postcode 26401 are $439.2 \%$ more likely to purchase the product "navi holiday up".

The discovered rules can be transformed directly into the form of business rules - e.g. into the JBoss Drools system, as described in (Vojir et al., 2013). The discovered rule is for the purposes of the JBoss Drools system transformed into the following form:

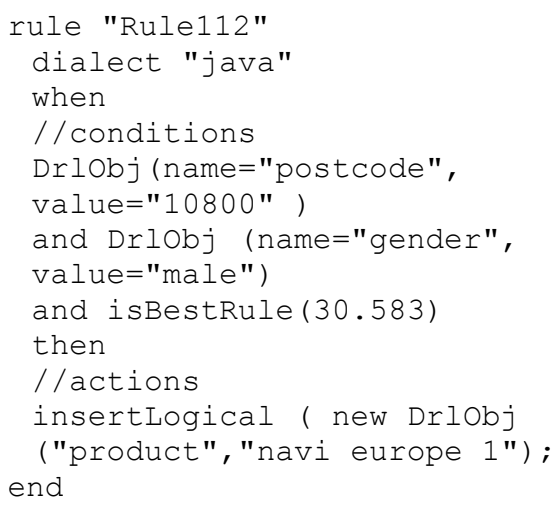

Similar rules that make it easier to target offers at end users are also the rules concerning preferred delivery method - according to available data either directly for a particular user according to their previous activity (example rule 3), or by the preferred method of recommendation according to users who live in the same area (town/city) (example rules 4-6). Examples of rules:

(3) User (e7dbb6bcc56c077f30f844ae) -> Delivery method(PPL to household) [Confidence: 1]

(4) town (Rakovnik) \& postcode (73571) $->$ delivery (PPL to household) [Confidence: 1 ]

(5) postcode (70200) $\rightarrow$ delivery (PPL to firm) [Confidence: 0.846]

(6) town (Klatovy) \& postcode (33901) \& gender $(\mathrm{m}) \quad \rightarrow$ payment (cash on delivery CR) [Confidence: 0.833 ]

A series of data mining tasks was solved as part of the data analysis, which led to finding a corresponding number of results. If the number of rules is too large, it increases enormously the computational complexity of the model; therefore the aim was to get hundreds of rules at most in the individual tasks. The values of rates of interest were gradually modified for this purpose - mainly Support. When finding characteristics related to groups of customers, brCBA algorithm was also used.

The numbers of rules acquired in two selected tasks are given as an illustration. In the solution of the task characterizing the relation of the month of previous purchase, gender and product category to the offered product, using a set minimal Confidence values of 0.6, 266 association rules were found. In another task characterizing the relation of groups of customers defined by place of residence (town/city and postcode) and gender to delivery and payment method, using minimal Confidence values of 0.6 and Support with an absolute value of 5 records, 570 rules were found.

\section{Combination with Other Business Rules}

As was mentioned in the description of the method in step three, it is suitable to combine business rules acquired by using data mining tasks with other already existing rules and dependencies. The discovered rules should be complemented by two basic kinds of information:

- Rules describing the compatibility of individual products (the compatibility of a particular GPS navigation with accessories and specific types of map data)

Information about the availability of individual products (it certainly should not happen in a marketing campaign that the offered products are not currently available in a short delivery time)

The final component of the created business rule set are rules defining events that trigger the activation of a specific marketing activity. In this case, it is the timer for sending e-mail offers, e.g. when the latest order has been completed.

\section{Discussion, Advantages and Limitations of the Proposed Method}

The area that focuses on creating personalized marketing strategies is wide and it is always narrowly connected to a particular firm and its possibilities. In this respect, it is mainly the company's ability to acquire and process customer data. These data then define the firm's capacity to approach customers at a direct line between mass and individual communication. For the implementation of the proposed method, that uses mining association rules by the GUHA method and their subsequent conversion to business rules, were suggested to use freely available technologies - LISp-Miner and JBoss Drools. Companies are thus not burdened with further costs for purchasing software licences.

Apart from a technological solution for creating business rules and subsequent work with them, the article also described the types of customer data required for creating individualized offers. The focus was on mining rules from historical data (customers' orders), because there is a direct connection to creating individualized e-mailing campaigns. The proposed method can also be used for similar tasks - e.g. real-time personalization of product offers displayed on e-shop website. In this case, it would be suitable to use - apart from historical data about orders - also clickstream data in order to obtain relevant information about the browsing patterns of web users. The process of acquiring new business rules should be repeated, depending on the historical data that are already available.

In the field of marketing, there are also other methods for personalization of individual offers. The main advantage of using the method of learning business rules for marketing activities lies in the possibility of their combination with other, manually defined (written) 
business rules. Business rules as a concept are based on the terms used in a particular firm and are clear enough not only for data mining experts but also for managers and people from the marketing department. Compared with other data mining methods, the GUHA association rules gained using the procedure 4ft-Miner have rich semantics, but they are still fully explainable and understandable (Berka, 2005; Rauch \& Simunek, 2014). After conversion to business rules, an expert or manager can customize the rule set, edit individual rules and add their own rules. Business rules are a suitable approach for separating business logic from the code of information systems and business processes. The same business rule management system can manage and execute business rules for marketing activities as well as other business rules defined and used in the firm.

The main limitation of the presented method is the fact that it is demanding in terms of the historical data that can be used for solving data mining tasks. In order to find rules, it is necessary to have records about at least hundreds or thousands of orders. For older data, it is also suitable to have information about the categorization of products. Since offered items are gradually updated, it is also suitable in many cases to have information about the category from which a newer item is to be selected.

When mining association rules for the purpose of classification and recommendation, it is suitable to use low threshold values of rates of interest. Data mining models created in this way achieve good results, in which they are comparable with (in some cases even better than) commonly used classification models (e.g. decision trees). A disadvantage of a model based on association rules is the large number of rules (Kliegr et al., 2014). It is suitable to insert these rules in a business rule system into a conditioned rule subset - in order to maintain the transparency a manageability of the whole business rule base. In terms of the demands of the subsequent recommendation, models containing thousands of rules were successfully tested in practice. With a number of rules of a greater order, the computational and time demands of the created inference base increase, which limits its applicability, e.g. when displaying offers as part of a request to load an e-shop website in the case of website personalization.

\section{Conclusion and Future Direction of Research}

The presented artefact in form of a method enables companies to create personalized offers using historical customer data. This method is intended for general use, but the practical demonstration from the selected e-shop emphasizes creating personalized e-mailing. This practical example confirmed that this method is technologically feasible, even when using freely available tools, and at the same time answers the needs of firms in the area of personalized marketing.

This method can also be integrated into broader personalized marketing strategies, which can be built on using further data, tools or technological artefacts. Concerning the future development of the proposed method, it would be interesting to aggregate data from multiple sources (e.g. social media) and thus create business rules that would relate generally to the activities of a website user (not only a customer). This approach would be suitable mainly for automatic personalized product recommendation on the web. Interesting for future design type of research would also be the feedback provided by quantitative or qualitative research that would follow the application of personalized marketing strategies, including the method suggested for a selected company. Such results would help develop personalized marketing and define new areas that need to be covered by designing new artefacts

\section{Acknowledgement}

This work was carried out within the project VSE IGS F4/29/2016 financially supported by the University of Economics, Prague.

\section{References}

Agrawal, R., Imielinski, T., \& Swami, A. (1993). Mining Association Rules between Sets of Items in Large Databases. ACM SIGMOD, 22(2), 207-216. http://dx.doi.org/10.1145/170036.170072

Bae, J. H., Sho, S. H., \& Choi, L. K. (2012). Designing Mobile Framework for Intelligent Personalized Marketing Service in Interactive Exhibition Space. Journal of Intelligence and Information Systems, 18(1), 59-69.

Becan, M., \& Smutny, Z. (2016). The Use of Enterprise Social Networks in Organizations from the Perspective of Generation $\mathrm{Y}$ in the Czech Republic. Scientific Annals of Economics and Business, 63(1), 83-96. http://dx.doi.org/10. 1515/saeb-2016-0106

Benson, V., Saridakis, G., \& Tennakoon, H. (2015). Information disclosure of social media users: does control over personal information, user awareness and security notices matter?. Information Technology \& People, 28(3), 426441. http://dx.doi.org/10.1108/ITP-10-2014-0232

Berka, P. (2005). Dobyvani znalosti z databazi [Knowledge discovery in databases]. Prague: Academia.

Berka, P. (2011). ETree Miner: A New GUHA Procedure for Building Exploration Trees. In M. Kryszkiewicz, H. Rybinski, A. Skowron, Z. W. Ras (Eds.) Foundations of Intelligent Systems: Volume 6804 of the Series Lecture Notes in Computer Science (pp. 96-101). Berlin: Springer. http://dx.doi.org/10.1007/978-3-642-21916-0_11

Berka, P. (2016). Using the LISp-Miner System for Credit Risk Assessment. Neural Network World, 26(5), $497-518$. http://dx.doi.org/10.14311/NNW.2016.26.029 
Bhardwaj, S., Atrey, P. K., Saini, M. K., \& El Saddik, A. (2015). Personality assessment using multiple online social networks. Multimedia Tools and Applications, (in press). http://dx.doi.org/10.1007/s11042-015-2793-0

Bing, L., Wynne, H., \& Yiming, M. (1998). Integrating classification and association rule mining. In R. Agrawal, P. Stolorz (Eds.), Proceedings of the fourth international conference on knowledge discovery and data mining (pp. 8086). Palo Alto: American Association for Artificial Intelligence.

Bosch. (2010). The Past, Present, and Future of Business Rules: Towards True Business Enablement. [White paper], Bosch Software Innovations. Available from internet: https://www.bosch-si.com/media/bosch_software _innovations/documents/white_paper/brm/2012-03_Business_Rules_History_EN.pdf

Dresch, A., Lacerda, D. P., \& Antunes Jr., J. A. V. (2015). Design Science Research: A Method for Science and Technology Advancement. New York: Springer.

Estrella-Ramon, A. M., Sanchez-Perez, M., Swinnen, G., \& VanHoof, K. (2013). A marketing view of the customer value: Customer lifetime value and customer equity. South African Journal of Business Management, 44(4), 47-64.

Fader, P. S. (2012). Customer Centricity: Focus on the Right Customers for Strategic Advantage. Philadelphia: Wharton Digital Press.

Goldsmith, R. E., \& Freiden, J. B. (2004). Have it your way: consumer attitudes toward personalized marketing. Marketing Intelligence \& Planning, 22(2), 228-239. http://dx.doi.org/10.1108/02634500410525887

Guelman, L., Guillen, M. \& Perez-Marin, A.M. (2015). A decision support framework to implement optimal personalized marketing interventions. Decision Support Systems, 72, 24-32. http://dx.doi.org/10.1016/j.dss.2015.01.010

Gwynn, S. (2016). Most consumers reject personalised marketing, study shows. Available from internet: http://www.campaignlive.co.uk/article/consumers-reject-personalised-marketing-study-shows/

Hajek, P., Havel, I., \& Chytil, M. (1966). The GUHA method of automatic hypotheses determination. Computing, 1(4), 293-308. http://dx.doi.org/10.1007/BF02345483

Hajek, P., Holena, M., \& Rauch, J. (2010). The GUHA method and its meaning for data mining. Journal of Computer and System Sciences, 76(1), 34-48. http://dx.doi.org/10.1016/j.jcss.2009.05.004

Hay, D., Healy, K. A., \& Hall, J. (2000). Defining business rules - What are they really. [Final Report], Business Rules Group. Available from internet: http://www.businessrulesgroup.org/first_paper/BRG-whatisBR_3ed.pdf

Hevner, A. R., March, S. T., Park, J., \& Ram, S. (2004). Design Science in Information Systems Research. MIS Quarterly, 28(1), 75-105.

Holena, M. (1998). Fuzzy hypotheses for GUHA implications. Fuzzy Sets and Systems, 98(1), 101-125. http://dx.doi.org/10.1016/S0165-0114(96)00369-7

Jones, C., \& Shao, B. (2011). The Net Generation and Digital Natives. Walton Hall: The Open University.

Kliegr, T., Kuchar, J., Sottara, D., \& Vojir, S. (2014). Learning business rules with association rule classifiers. In A. Bikakis, P. Fodor, D. Roman (Eds.), Rules on the Web: From Theory to Applications (pp. 236-250). Berlin: Springer. http://dx.doi.org/10.1007/978-3-319-09870-8_18

Kliegr, T., \& Rauch, J. (2010). An XML format for association rule models based on the GUHA method. In M. Dean et al. (Eds.), International Workshop on Rules and Rule Markup Languages for the Semantic Web (pp. 273-288). Berlin: Springer. http://dx.doi.org/10.1007/978-3-642-16289-3_23

Menon, R. G. V., \& Sigurdsson, V. (2016). Conjoint Analysis for Social Media Marketing Experimentation: Choice, Utility Estimates and Preference Ranking. Managerial and Decision Economics, 37(4-5), 345-359. http://dx.doi.org/10.1002/mde.2721

Micheaux, A. L. (2011). Managing e-mail advertising frequency from the consumer perspective. Journal of Advertising, 40(4), 45-66. http://dx.doi.org/10.2753/JOA0091-3367400404

Moreno, A., Navarro, C., Tench, R., \& Zerfass, A., 2015. Does social media usage matter? An analysis of online practices and digital media perceptions of communication practitioners in Europe. Public Relations Review, 41(2), $242-253$. http://dx.doi.org/10.1016/j.pubrev.2014.12.006

Normantas, K., \& Vasilecas, O. (2014). Extracting term units and fact units from existing databases using the Knowledge Discovery Metamodel. Journal of Information Science, 40(4), 413-425. http://dx.doi.org/10.1177/016555 1514526336

Persson, A., \& Ryals, L. (2010). Customer assets and customer equity: Management and measurement issues. Marketing Theory, 10(4), 417-436. http://dx.doi.org/10.1177/1470593110382828

Piche, R., Jarvenpaa, M., Turunen, E., \& Simunek, M. (2014). Bayesian analysis of GUHA hypotheses. Journal of Intelligent Information Systems, 42(1), 47-73. http://dx.doi.org/10.1007/s10844-013-0255-6

Red Hat. (2016). Drools - Overview. Available from internet: http://www.drools.org

Rauch, J. (2013). Observational Calculi and Association Rules. Berlin: Springer. 
Stanislav Vojir, Zdenek Smutny. Business Rules Mining Using GUHA Method for the Personalization of Commercial...

Rauch, J., \& Simunek, M. (2014). Dobyvani znalosti z databazi, LISp-Miner a GUHA [Knowledge discovery in databases, Lisp-Miner and GUHA]. Prague: Oeconomica.

Rauch, J., \& Simunek, M. (2009). Action Rules and the GUHA Method: Preliminary Considerations and Results. In J. Rauch, Z. W. Ras, P. Berka, T. Elomaa (Eds.) Foundations of Intelligent Systems: Volume 5722 of the series Lecture Notes in Computer Science (pp. 76-87). Berlin: Springer. http://dx.doi.org/10.1007/978-3-642-04125-9_11

Rauch, J., \& Simunek, M. (2001). Mining for Association Rules by 4ft-Miner. In INAP 2001 - Proceeding of the International Conference On Applications of Prolog (pp. 285-294). Tokyo: REN Associates.

Ross, R. G. (2003). Principles of the Business Rule Approach. Indianapolis: Addison-Wesley Professional.

Ryals, L., \& Knox, S. (2007). Measuring and managing customer relationship risk in business markets. Industrial Marketing Management, 36(6), 823-833. http://dx.doi.org/10.1016/j.indmarrnan.2006.06.017

Shen, A. Y. (2014). Recommendations as personalized marketing: insights from customer experiences. Journal of Services Marketing, 28(5), 414-427. http://dx.doi.org/10.1108/JSM-04-2013-0083

Sigurdsson, V., Hinriksson, H., \& Menon, R. G. V. (2016). Operant Behavioral Economics for E-mail Marketing: An Experiment Based on the Behavioral Perspective Model Testing the Effectiveness of Motivational Operation, Utilitarian and Informational Stimuli. Managerial and Decision Economics, 37(4-5), 337-344. http://dx.doi.org/10. 1002/mde. 2725

Simunek, M. et al. (2016). The official site of the LISp-Miner project. Available from internet: http://lispminer.vse.cz/

Smutny, Z., Janoscik, V., \& Cermak, R. (2017). Generation Y and Internet Privacy: Implication for Commercialization of Social Networking Services. In V. Benson, R. Tuninga, G. Saridakis (Eds.), Analyzing the Strategic Role of Social Networking in Firm Growth and Productivity. Reading: IGI Global. http://dx.doi.org/10.4018/978-1-5225-05594.ch006

Tan, P. N., Steinbach, M., \& Kumar, V. (2005). Introduction to Data Mining. New York: Pearson.

Tang, H., Liao, S. S., \& Sun, S. X. (2013). A prediction framework based on contextual data to support Mobile Personalized Marketing. Decision Support Systems, 56, 234-246. http://dx.doi.org/10.1016/j.dss.2013.06.004

Teradata. (2015). Teradata 2015 Global Data-Driven Marketing Survey. Available from internet: http://www.teradata.com/ DDMSurvey2015

Tucker, C. E. (2014). Social Networks, Personalized Advertising, and Privacy Controls. Journal of Marketing Research, 51(5), 546-562. http://dx.doi.org/10.1509/jmr.10.0355

Vaishnavi, V., \& Kuechler, B. (2015). Design Science Research in Information Systems. Available from internet: http://desrist.org/desrist/content/design-science-research-in-information-systems.pdf

Vesanen, J. (2007). What is personalization? A conceptual framework. European Journal of Marketing, 41(5/6), 409-418. http://dx.doi.org/10.1108/03090560710737534

Vojir, S., Kliegr, T., Hazucha, A., Skrabal, R., \& Simunek, M. (2013). Transforming Association Rules to Business Rules: EasyMiner meets Drools. In P. Fodor et al. (Eds.), Joint Proceedings of the 7th International Rule Challenge (pp. 1-13). Aachen: CEUR-WS.

Wieringa, R. J. (2014). Design Science Methodology for Information Systems and Software Engineering. New York: Springer.

Winter, R. (2008). Design science research in Europe. European Journal of Information Systems, 17, $470-475$. http://dx.doi.org/10.1057/ejis.2008.44

Xavier, A. C. (2011). Digital literacy: Impacts of technology on learning from Generation Y. Calidoscopio, 9(1), 3-14. http://dx.doi.org/10.4013/cld.2011.91.01

Zamecnikova, E., \& Kreslikova, J. (2016). Business Rules Definition for Decision Support System Using Matrix Grammar. Acta Informatica Pragensia, 5(1), 72-81. http://dx.doi.org/10.18267/j.aip.86

Zarghami, A., Sapkota, B., Eslami, M. Z., \& Van Sinderen, M. (2012). Decision as a service: Separating decision-making from application process logic. In Proceedings of the 2012 IEEE 16th International Enterprise Distributed Object Computing Conference, EDOC 2012 (pp. 103-112). New York: IEEE. http://dx.doi.org/10.1109/EDOC.2012.21

The article has been reviewed.

Received in July, 2016; accepted in April, 2017. 